\title{
A REFLEXÃO BIOÉTICA NA GESTÃO UNIVERSITÁRIA NO MODELO DA ECONOMIA DE COMUNHÃO E A ATUAÇÃO DO OMBUDSMAN
}

\author{
Carlos Ferrara Junior ${ }^{1}$ \\ Ana Maria Lombardi Daibem ${ }^{2}$
}

\section{Resumo}

O trabalho subordinado na Gestão Universitária e o poder diretivo do empregador se entrelaçam no cotidiano das relações laborativas por força do mesmo contrato de trabalho contrapondo de um lado o empregado, pessoa física que exerce atividades mediante salário, subordinação, habitualidade e pessoalidade, e do outro o empregador responsável pela direção das atividades prestadas. Este contexto destaca o limite do poder diretivo em respeito à dignidade do profissional que cumpre com o objetivo fim da empresa e a sua função social no mercado empresarial. $\mathrm{O}$ escopo deste artigo consiste no entender como o Ombudsman pode auxiliar na denominada Economia de Comunhão, especificamente no poder diretivo dos gestores frente ao corpo docente, viabilizando uma gestão universitária satisfatória com trocas humanas de alteridade em respeito à valorização da dignidade profissional, buscando uma reflexão bioética. A pesquisa realizada foi exploratória, descritiva e explicativa a partir de revisão bibliográfica, objetivando a verdade por meio de uma atitude crítica e racional. $A$ convivência em ambiente onde docentes e demais profissionais da gestão universitária agem nos estreitos limites do contrato de trabalho pode gerar uma convivência altamente insatisfatória. Esta atuação deve estar pautada na chamada gratuidade, diferente da gentileza e da boa educação ou de uma simples beneficência. Essa gentileza só existe se a gestão respeitar a dignidade profissional pautada nas premissas do direito à autonomia, do dever de não maleficência e na avaliação crítica de benefícios frente aos riscos, o que coíbe a existência de assédio moral.

Palavras-chave: Bioética. Vulnerabilidade. Alteridade. Assédio Moral. Economia de Comunhão. Ombudsman.

\section{DOI:10.37814/2594-5068.2018v1.p63-81}

1 Cirurgião-Dentista. Advogado. Doutor em Bioética. Mestre em Direito. Especialista em Saúde Pública, Administração Hospitalar e Direito do Trabalho. Certificado em Ouvidoria. Docente no Centro Universitário São Camilo. (ferrara@saocamilo.br) Avenida Pompeia, 888 - Vila Pompeia - CEP 05022-000 - 011996860956

2 Pedagoga. Doutora e Mestra em Educação. Docente no Centro Universitário São Camilo. (amdaibem@gmail.com) Avenida Pompeia, 888 - Vila Pompeia - CEP 05022-000 fone: 01499724722. 


\section{Abstract}

The subordinate work in the University Management and the directive power of the employer are intertwined in the quotidian of the labor relations by virtue of the same contract of work opposing on the one hand the employee, physical person who carries out activities through salary, subordination, habituality and personality, and of the other, the employer responsible for the direction of the activities provided. This context highlights the limit of the directive power in respect to the dignity of the professional that fulfills the objective end of the company and its social function in the business market. The scope of this article is to understand how the Ombudsman can help in the denominated Economy of Communion, specifically in the directive power of the managers in front of the faculty, enabling a satisfactory university management with human exchanges of alterity in respect to the valorization of the professional dignity, seeking a bioethical reflection. The research was exploratory, descriptive and explanatory from a bibliographical review, objectifying the truth through a critical and rational attitude. Coexistence in an environment where teachers and other university management professionals act within the narrow limits of the employment contract can generate a highly unsatisfactory coexistence. This action must be based on the so-called gratuity, different from the kindness and good education or a simple beneficence. This kindness exists only if the management respects the professional dignity based on the premises of the right to autonomy, the duty of non-maleficence and the critical evaluation of benefits against risks, which prohibits the existence of moral harassment.

Keywords: Bioethics. Vulnerability. Otherness. Moral Harassment. Economy of Communion. Ombudsman. 


\section{INTRODUÇÃO}

\subsection{A Bioética}

A Bioética se apresenta como uma nova disciplina, que combinaria então os conhecimentos biológicos com o conhecimento dos sistemas de valores humanos. No termo Bioética, bio representa os conhecimentos biológicos e ética, o conhecimento dos sistemas de valores humanos. A nova disciplina deveria construir uma ponte entre essas duas culturas, a cultura das ciências naturais e a cultura das ciências humanas, superando a lacuna existente entre elas.

Há 46 (quarenta e seis anos), na Universidade de Wisconsin, em Madison, D.C., Van Rensselaer Potter, por ocasião da publicação de seu primeiro artigo nos Estados Unidos, propõe o termo "bioética" com o conceito "Bioética como ponte para o futuro" (PESSINI, 2014, p. 6). Ponte entre ciência biológica e ética, mas como um meio para um fim, "ponte para o futuro" - disciplina que guiaria a humanidade, atribuindo a ela sentido em direção ao futuro (BARCHIFONTAINE, 2012).

No ano seguinte, Potter lança o livro Bridge to the future, onde podemos ler na contracapa:

Ar e água poluída, explosão populacional, ecologia, conservação - muitas vozes falam, muitas definições são dadas. Quem está certo? As ideias se entrecruzam e existem argumentos conflitivos que confundem as questões e atrasam a ação. Qual é a resposta? O homem realmente está colocando em risco o seu meio ambiente? Não seria necessário aprimorar as condições que ele criou? A ameaça de sobrevivência é real ou se trata de pura propaganda de alguns teóricos histéricos? Esta nova ciência, bioética, combina o trabalho dos humanistas e cientistas cujos objetivos são sabedoria e conhecimento. A sabedoria é definida como o conhecimento de como usar o conhecimento para o bem social. A busca de sabedoria tem uma nova orientação porque a sobrevivência do homem está em jogo. Os valores éticos devem ser testados em termos de futuro e não podem estar distantes dos fatos biológicos. Ações que diminuem as chances de sobrevivência humana são imorais e devem ser julgadas em termos do conhecimento disponível e no monitoramento de parâmetros de sobrevivência que são escolhidos pelos cientistas e humanistas. (POTTER, 1971)

Assim, o objetivo da bioética, ao adotar uma postura interdisciplinar, considera em um só campo os conhecimentos da biologia e da ética, com vistas a fornecer elementos à humanidade para caminhar em direção a uma participação racional, mas cautelosa, no processo da evolução biológica e cultural.

\subsection{Conceitualizações da Bioética}

As dimensões éticas examinadas na bioética tendem a enfocar várias questões maiores: qual é a visão moral da pessoa ou da sociedade? Que tipo de pessoa humana devemos ser? Que tipo de sociedade devemos construir? O que deve ser feito em situações específicas? Como vivermos harmoniosamente? A Bioética pode ser tomada, inicialmente, como um movimento social que lutava pela ética nas ciências biológicas e áreas correlatas, antes de ser uma disciplina norteadora de teorias para o Biodireito e para a legislação. A finalidade primeira da bioética foi a de assegurar 
mais humanismo nas ações do cotidiano das práticas médicas e nas experimentações científicas que utilizam seres humanos. Essa visão, tanto de disciplina como de movimento social, confere à bioética a peculiaridade de ser, ao mesmo tempo, um campo de reflexão e ação sobre as questões do presente e as perspectivas de futuro quanto à saúde das populações (OLIVEIRA, 1997).

A Bioética é uma nova maneira de enfocar a ética nas ciências da vida e da saúde, que combina estudo e reflexão e traça uma ponte entre as ciências biológicas e humanas, por meio de um diálogo inclusivo, plural e responsável, na busca de sabedoria, entendida como o conhecimento usado para o bem social e promoção da dignidade humana e da boa qualidade de vida para todos (OGUISSO e ZOBOLI, 2006).

Assim, a Bioética é ética da vida, da saúde e do meio ambiente. Não se pode dela esperar uma padronização de valores, pois exige uma reflexão sobre esses e, como dito, implica opção. Ora, opção implica liberdade. Não há Bioética sem liberdade, liberdade para se fazer opção, por mais "angustiante" que possa ser. O exercício da Bioética exige, pois, liberdade e opção. E esse exercício deve ser realizado sem coação, sem coerção e sem preconceito e por meio de deliberação. É um processo de reflexão e ação procurando o melhor para as pessoas. Dessa maneira, as sociedades democráticas são mais propícias à Bioética (BARCHIFONTAINE, 2012).

Bioética, ética da vida, é um espaço de diálogo transprofissional, transdisciplinar e transcultural na área da saúde e da vida, um grito pelo resgate da dignidade da pessoa, dando ênfase na qualidade de vida: proteção à vida humana e seu ambiente. Não é ética pré-fabricada, mas um processo (BARCHIFONTAINE, 2004).

\section{A GESTÃO DO AMBIENTE ACADÊMICO}

A gestão do ambiente acadêmico compreende a assunção de uma determinada proposta institucional, formada na prática por um conjunto que envolve diversos núcleos - político, administrativo, técnico, cultural, educativo entre outros - que necessitam ser pensados como um todo equilibrado e não de forma segmentada (SACRISTÁN e GÓMEZ, 1998).

Esse assunto se revela de forma destacada, uma vez que os envolvidos, aqueles que atuam no ambiente acadêmico, não estão acostumados ao exercício laboral de forma integrada, seja pela não profissionalização das instituições em alguns casos, e aqui destacamos as empresas familiares, seja pelo não conhecimento global do mercado educacional, seja pela necessidade de atingir resultados de produção que parecem constituir-se em um mundo à parte das propostas pedagógicas estipuladas e não seguidas ou, ainda, pelo total desconhecimento da importância e consequentemente necessidade da prática acadêmica de forma global visando o perfeito equilíbrio de uma gestão pensada no sucesso acadêmico, tanto por parte do corpo discente, como do docente e técnico-administrativo, além do resultado mercadológico almejado pela Instituição de Ensino Superior privada.

Aliada a essa necessidade, existe na gestão acadêmica a figura não de um ator propriamente dito, mas sim de um sistema acadêmico integrador, ferramenta tecnológica que deve se somar à gestão dessas relações humanas. 


\subsection{A Gestão Acadêmica}

Nos últimos anos, as Instituições de Ensino Superior (IES) vêm sofrendo pressão de um mercado cada vez mais competitivo e especialmente agressivo, levando-as a explorar o planejamento estratégico institucional como principal atributo para sua sobrevivência. Hoje, foca-se nos resultados e, como consequência, os métodos de cobrança são muito diferentes dos até então praticados, como por exemplo os de uma empresa educacional familiar.

Com efeito, e em decorrência desse novo panorama, houve alteração do perfil funcional de profissionais que são contratados pelas Escolas Superiores, ou seja, até então os agentes da educação superior eram regrados e disciplinados, com gestão altamente centralizada, e atualmente encontramos profissionais autônomos, dinâmicos, inovadores e empreendedores visando a busca da perenidade institucional dentro de uma possibilidade descentralizada, com maior autonomia e responsabilidade individual como atributos desejáveis e necessários.

O ambiente externo às IES muda de forma intermitente e, com isso, a organização educacional deve se adaptar a essa constante mudança. Os gestores devem pensar e planejar de forma estratégica. Essa mudança de paradigmas na gestão deve ser implantada de forma gradual, considerando o capital humano de seus profissionais, que também deve ter a oportunidade de adaptação ao novo modelo. Para isso, a formação contínua é necessária porque o ambiente em constante mudança leva as empresas educacionais e seus gestores a possíveis eventos inesperados, e esses profissionais devem estar preparados para a correção de rota tão comum nesses casos.

Portanto, foca-se atualmente no desempenho, seja dos gestores, seja do corpo técnico-administrativo, incluindo-se o Ombudsman até mesmo do corpo docente. O grande desafio é alinhar os objetivos individuais com os objetivos organizacionais, e para isso o colaborador deve contar, de forma clara, com um plano de ação, diante da concorrência tão acirrada, que determine especialmente quais são as entregas necessárias e esperadas a fim de obter resultados satisfatórios.

O grande desafio diante desse novo cenário é criar e manter um ambiente harmonioso e produtivo, em que o respeito, a confiança, a autoestima e a satisfação no trabalho sejam priorizados, com a dose certa do Poder Diretivo do Empregador sendo aplicada, para que os colaboradores estejam alinhados e comprometidos com os valores institucionais sempre atrelados à sua valorização como profissional.

Como enfrentar de forma exitosa esse novo cenário? Certamente, diante da necessidade de efetivar a mudança, as organizações educacionais devem buscar aprimorar seus processos para produzir o melhor, no menor tempo e no mais baixo custo possível (melhor, rápido e com economia). Tudo culminando na satisfação dos alunos e valorização como profissionais da educação, além do comprometimento de todos os colaboradores. Entretanto não se pode esquecer o processo de regulação e supervisão do Ministério da Educação para os cursos de graduação e pós-graduação stricto sensu e, num futuro próximo, para os cursos de pós-graduação lato sensu, que estabelece indicadores de qualidade do ensino superior. Portanto, entendemos que a gestão acadêmica deve buscar uma cooperação solidária entre seus colaboradores para atingir a transformação como produto em novas ações institucionais, sempre focando na valorização da dignidade profissional. 
É nesse cenário que hoje o profissional Ombudsman é fonte para discussões na movimentada academia, traduzindo-se em melhorias e fortalecimento da gestão. Temos portanto pontos importantes que devem ser considerados, como autonomia universitária (para universidades e centros universitários), dimensão política da escola, índices de performance institucional (pelo Ministério da Educação ou por autoavaliação), poder decisório, financiamentos, indicadores quantitativos e qualitativos através de relatórios bem elaborados, perspectiva a longo prazo mas de forma particular e especial, formação de gestores universitários com especificidades e habilidades desenvolvidas nessa área, que vão desde os membros dos conselhos superiores, perpassando pelas lideranças acadêmicas e administrativas que consigam compreender o cotidiano de uma universidade (com competência acadêmica), culminando no quadro docente compromissado com as novas possibilidades, incluindo-se nesse contexto o Ensino a Distância (EaD).

\section{O MEIO AMBIENTE DO TRABALHO EDUCACIONAL}

A preocupação com o meio ambiente começou de forma tímida e, como bem assinalava o Prof. Dr. Domingos Sávio Zainaghi em suas aulas na UNIFIEO - Centro Universitário FIEO, ao longo do programa de Mestrado em Direitos Humanos, inicialmente a preocupação era voltada tão somente à defesa do mico-leão-dourado, da madeira de lei em determinadas regiões do país (ZAINAGHI, 2003).

Tal situação posteriormente culminou com igual proteção em relação ao homem que ali vivia. Assim é que o conceito de meio ambiente passou a alcançar outras dimensões e se voltar para o destinatário da norma, que é precipuamente a pessoa humana.

O homem, enquanto ser vivente, integra, como tal, o mundo da natureza e, nesse prisma, tem tanto direito à vida quanto tudo o mais que compõe os reinos animal e vegetal (MANCUSO, 1990).

Todavia, é inegável que os horizontes do homem vão muito além do mero instinto de sobrevivência, considerando que sua alma revela uma natural tendência ao progresso, ao desenvolvimento e à realização, mesmo em condições de severa adversidade. Nem outra coisa sinaliza a mensagem cristã de que "nem só de pão vive o homem" ou o alerta do Nazareno no sentido de que viera para "que todos tenham vida e tenham em abundância", mensagem consoante com a diretriz da "qualidade de vida" enunciada na Constituição Federal em seu artigo 225.

Na lição de MANCUSO (1990), não resta dúvida de que está assegurada a autonomia conceitual do meio ambiente do trabalho, uma subespécie do meio ambiente artificial ou construído, ou seja, o "habitat laboral" onde o homem deva encontrar os meios que haverão de prover sua existência digna.

Assinala ainda que o conceito básico de meio ambiente é o do artigo $3^{\circ}$ da Lei 6.938 de 1.981 , que instituiu a Política Nacional do Meio Ambiente e criou o Sistema Nacional de Preservação e Controle (SISNAMA): "O conjunto de condições, leis, influências e interações de ordem física, química e biológica, que permite, abriga e rege a vida em todas as suas formas".

Adiante, algumas definições de meio ambiente do trabalho.

SILVA (1998) escreve que o meio ambiente do trabalho vem a ser o "habitat laboral", isto é, 
tudo que envolve e condiciona, direta ou indiretamente, o local onde o homem obtém os meios para prover o quanto necessário para sua sobrevivência e desenvolvimento, em equilíbrio com o ecossistema. A contrario sensu, portanto, quando aquele "habitat" se revele inidôneo a assegurar as condições mínimas para uma razoável qualidade de vida do trabalhador, aí se terá uma lesão ao meio ambiente do trabalho.

\subsection{Os Atores Acadêmicos}

Como já apontamos, as IES vêm sofrendo ao longo do tempo a pressão de um mercado cada vez mais competitivo e especialmente agressivo.

Atualmente, os atores acadêmicos estão com seu perfil alterado. Inicialmente, ao longo da história das Instituições de Ensino Superior, contávamos com profissionais disciplinados e pouco criativos. Cumpriam as decisões estabelecidas pelos seus gestores. Hoje, o que se procura por ocasião de nova contratação são profissionais ousados, agressivos sob o ponto de vista do mercado, criativos, empreendedores e, por que não dizer, autônomos em suas ações no sentido de agregar sucesso junto à empresa educacional. Esses novos profissionais devem estar capacitados para essa atuação, sempre com muita responsabilidade e ética.

Porém, a incerteza dos mercados econômico, tecnológico, cultural, social e certamente educacional faz com que invariavelmente ocorram mudanças na gestão das IES visando focar em melhorias e inovações para sua manutenção no mercado educacional.

Para tanto, várias estratégias devem ser pensadas em conjunto para que seu posicionamento se mantenha, apesar de que em algumas circunstâncias, e não são incomuns, a governança atinja patamares muitas vezes desconhecidos inicialmente. Esse é exatamente o ponto crucial do sucesso e sua permanência ativa nesse mundo educacional, cheio de incertezas na atualidade. Afirma COOKE (in GOLDCHLEGER, IVOGLO e COLOMBO, 2013, p. 199) que uma estratégia de desenvolvimento deve assegurar a uma organização ser eficaz respondendo adequadamente às mudanças em seu ambiente interno e externo e fazendo o melhor uso das capacidades individuais e coletivas de seus profissionais.

Portanto, a estratégia de Recursos Humanos deve acompanhar essa necessidade, seja para adequação ao novo meio ambiente de trabalho proposto e necessário ou para a manutenção do posicionamento da marca diante da concorrência agressiva.

Os atores, comunidade acadêmica de docentes, os técnico-administrativos, bem como os gestores, devem ter a consciência dessa mudança, e para tanto a formação se faz necessária e torna-se inerente a essa gestão, isso porque o desempenho passa a ser fundamental na visão dos mantenedores. Podemos então dizer que esse novo modelo esperado se torna sofisticado para driblar a concorrência acirrada. Salienta-se ainda a necessidade da autonomia com que o Ombudsman deve atuar dentro da esfera educacional, o que muitas vezes torna-se muito difícil do ponto de vista da gestão educacional. DUTRA (in GOLDCHLEGER, IVOGLO e COLOMBO, 2013, p.201) conceitua desempenho como o conjunto de entregas e resultados de determinada pessoa que a empresa ou negócio pode cobrar tendo em vista o contido no Contrato de Trabalho. 
Mister se faz salientar que a abordagem junto aos atores deve estar calcada sempre na valorização do ser humano, no trabalho em equipe e na perfeita orientação por parte dos gestores propriamente ditos, mas nunca esquecendo que a responsabilidade pelo sucesso da IES perpetua-se na atuação e responsabilidade de todos os envolvidos.

Mas, para que tudo assim possa acontecer, o recrutamento e a seleção devem estar atrelados a essa perspectiva de forma intrínseca. $\mathrm{O}$ que sabemos é que na atualidade os colaboradores de uma empresa, e na esfera da academia não é diferente, estão começando a procurar as empresas para sua atuação pelo que elas oferecem e não exclusivamente pela oferta momentânea de vagas.

Atualmente, os colaboradores esperam um meio ambiente do trabalho adequado livre de qualquer situação de desgaste ou assédio moral. Esse é um dos principais requisitos para escolha da empresa e o abordaremos em momento exclusivo ao longo deste trabalho acadêmico. Alguns especialistas na esfera trabalhista afirmam que o assédio moral é o "Mal do Século Empresarial".

Além do meio ambiente do trabalho adequado, apresentamos outras possibilidades desejadas por todos aqueles que procuram uma IES para laborarem:

- Boa visibilidade no mercado - as pessoas, especialmente os jovens talentos, procuram empresas que ofereçam seus serviços favoritos e valorizem seus currículos. Preferem empresas que estão constantemente na mídia. Essa perspectiva gera segurança e respeito profissional.

- Perspectivas de valorização profissional pautada na meritocracia, com planos de carreira homologados no Ministério do Trabalho, o que garante a ascensão profissional.

- Bolsas de Estudos não só dos cursos existentes na IES mas, especialmente e fundamentalmente, no exterior - capacitação constante e necessária para atuação responsável e a ascensão pela meritocracia.

- Contar com um parque estrutural adequado às suas propostas, com sistemas de registros acadêmicos modernos, salas de aulas confortáveis, bibliotecas atualizadas, laboratórios modernos com insumos à disposição, estação de trabalho funcional e ergonômica.

- Organização profissional, honesta e ética em suas ações, com metas claras e precisas de crescimento e segurança financeira.

- Responsabilidade Social demonstrada em ações concretas uma vez que esses novos profissionais estão dispostos a transformar o mundo e as pessoas envolvidas. A empresa deve propiciar condições para projetos de ações solidárias tanto na comunidade interna como no entorno da sede ou unidade/campus da IES.

\section{A INTERMEDIAÇÃO DO OMBUDSMAN}

\subsection{O Ombudsman e a Ouvidoria}

A palavra Ombudsman quer dizer de modo geral "pessoa que dá trâmite, o representante, o procurador, o defensor, aquele que representa". O Ombudsman foi oficializado pela Suécia em 
1809, com a finalidade de defender os cidadãos lesados em seus direitos pelo Estado. O Dicionário Aurélio define a palavra "Ombudsman" como sendo originada do sueco ombud, que quer dizer representante, deputado, acrescida do sufixo inglês man, que significa homem.

Assim, o Ombudsman, que no Brasil é mais conhecido como Ouvidor em instituições públicas, historicamente teve sua origem na Suécia. Temos, portanto, que nos países de democracia avançada como, por exemplo, a Suécia, o Ouvidor seria um funcionário do governo que investiga as queixas dos cidadãos contra os órgãos da Administração Pública. E, por extensão, a pessoa encarregada de observar e criticar as lacunas de uma Empresa, por exemplo, colocando-se no ponto de vista do cidadão usuário (público). Sua atividade foi aperfeiçoada com o passar do tempo, sendo que hoje em dia qualquer cidadão sueco pode apresentar reclamação diretamente ao Ombudsman, oralmente ou por escrito, sem qualquer ônus, sempre que se sentir ameaçado ou for lesado em seus direitos. Assim, desde 1809, a função do Ombudsman foi se espalhando pelo mundo, sendo adotada por vários países além da Suécia, tais como: Finlândia, Noruega, Dinamarca, Espanha, Nova Zelândia, Estados Unidos, Portugal, Rússia, Israel, Itália etc.

\subsection{O Ombudsman no Brasil}

No Brasil, a figura do Ouvidor está presente desde a época de 1538, quando o Sr. Antonio de Oliveira foi nomeado o primeiro Ouvidor por Dona Ana Pimentel, tendo acumulado o cargo de Ouvidor e Capitão-mor da Capitania de São Vicente. Na hierarquia do Brasil Colônia, o Ouvidor era a segunda autoridade com funções administrativas e judiciárias, sendo este, na realidade, o representante dos interesses da Coroa Portuguesa no Brasil.

A Constituição Federal de 1988 não contempla a figura de um Ouvidor para controle da Administração Federal, essa função fica a cargo dos Tribunais de Contas e do Ministério Público. Ressalta-se que, após o Encontro Nacional de Ouvidores realizado em Jaboatão dos Guararapes, no ano de 2001, ficou estabelecida em sua carta final a tentativa de inclusão do assunto na Constituição, através de um projeto de lei. Trata-se do Projeto de Lei - PL342/2007, de autoria do deputado Sergio Barradas Carneiro, cuja proposição visa instituir normas regulamentadoras da atividade de Ouvidor, cuja competência é criar um canal de comunicação com os clientes da empresa para receber reivindicações, reclamações e sugestões, bem como, a partir daí, recomendar medidas para implementação de melhorias em seus procedimentos e na qualidade dos produtos ou serviços que ofereça. Tal Projeto de Lei ainda tramita na Câmara dos Deputados.

A Constituição, em seu preâmbulo, estabelece que o Brasil é um Estado Democrático, destinado a assegurar o exercício dos direitos sociais e individuais, definindo, desta maneira, que o Estado nasce para servir ao homem e que não se sobrepõe ao cidadão. No capítulo intitulado Direitos e Deveres Individuais e Coletivos, no artigo $5^{\circ}$, está estabelecido que todos são iguais perante a lei, sem distinção de qualquer natureza. No artigo 37, tem-se que "os Poderes da União, dos Estados e dos Municípios obedecerão aos princípios da legalidade, impessoalidade, moralidade, publicidade e eficiência". O mesmo artigo, em seu $\S 3^{\circ}$, inciso I, assegura e estabelece o direito do usuário dos serviços públicos em reclamar. Por esta razão, vários níveis de governo (federal, 
estadual e municipal) têm adotado o Ouvidor em seus órgãos, com variados graus de sucesso em sua implantação.

O Estado Social e de Direito, obediente às suas próprias leis, conforme prelecionado em seu artigo $1^{\circ}$, tem como fundamento a soberania, a cidadania, a dignidade da pessoa humana, os valores sociais do trabalho, da livre iniciativa e do pluralismo político. Já no artigo $3^{\circ}$ temos que deve existir a construção de uma sociedade livre, justa e solidária, sendo este um dos objetivos fundamentais estabelecidos na Carta Magna. É o chamado processo de universalização que, no caso, diz respeito ao Ombudsman ou Ouvidor. Nota-se sua presença em vários hospitais, meios de comunicação, empresas do ramo do comércio, tanto públicos como privados.

Com o advento do Código de Defesa do Consumidor, as Ouvidorias Públicas e privadas ganham uma nova dimensão, haja vista a figura do cidadão-consumidor estar contemplada de forma direta, objetiva, clara e concisa. Hoje em dia, o cidadão sabe exatamente quais são os seus direitos bem como o procedimento desejável a ser adotado nas hipóteses desses direitos serem frustrados. Nesses casos, a Ouvidoria também está presente à medida que o cidadão busca a efetivação de seus direitos.

No Brasil, o Estado de São Paulo contempla a figura do Ouvidor em seu ordenamento jurídico por meio da Lei 10.294, de abril de 1999 - Lei de Proteção e Defesa do Usuário do Serviço Público -, que demonstra claramente o papel do Ouvidor bem como sua importância para o desenvolvimento e resgate da cidadania. O cidadão passa a ter direitos básicos como informação, qualidade na prestação dos serviços e o controle adequado ao Serviço Público.

Verifica-se, a partir da evolução histórica e de sua progressiva tendência à universalização, que as Ouvidorias têm contribuído para o aperfeiçoamento da máquina administrativa na esfera pública, bem como o "encantamento", satisfação e fidelização dos clientes na esfera privada, além de constituir-se em importante instrumento para a proteção individual dos cidadãos. Inicialmente voltada para o controle da Administração Pública, teve seu crescimento direcionado a outros organismos, devido sua potencialidade em obter mudanças, possibilitando a interação da organização com o ambiente externo e consolidando sua imagem perante a sociedade.

Cabe ao Ouvidor manter-se atualizado com as leis de defesa do consumidor, relacionar-se com a mídia e empresas, prestando informações sobre as suas funções. Deve ainda interagir com os órgãos de defesa do consumidor, procurando solucionar as manifestações dos cidadãos clientes. Finalmente, salientamos que o Ouvidor é um importante promotor da qualidade dentro da empresa e, por meio de sua atuação, a organização passa a conhecer o perfil de sua clientela, principalmente suas expectativas. Certamente, o sucesso de uma administração gerencial ocorre devido a adoção de posturas orientadas para o aperfeiçoamento dos processos e dos procedimentos, sempre visando a satisfação e o resgate da cidadania.

\subsection{Ouvidoria como Instrumento de Garantia de Direitos dos Cidadãos}

Não se pode falar em direitos dos cidadãos e cidadania sem correr risco de imprecisão, pois trata-se de um conceito largamente utilizado para diversos fins. Nesse caso, a cidadania como efe-

72 | Revista Científica da Associação Brasileira de Ouvidores/Ombudsman - Ano 1 - n 1 - 2017/2018 
tivação dos direitos do cidadão é a cidadania social, que se materializa neste estudo através da instalação de Ouvidorias como instrumento de garantia de direitos do cidadão, também compreendido como consumidor nos moldes jurídicos. O número de empresas que incluíram a função de Ouvidor em seus organogramas vem crescendo nos últimos anos. A razão desse impulso de respeito ao cidadão se explica, principalmente, por três bases - o aumento da responsabilidade social, a garantia de direitos constitucionais e a vigência do Código de Defesa do Consumidor -, que garantiram os meios jurídicos necessários para a cobrança pela melhoria dos serviços públicos e privados.

Constituem funções básicas de uma Ouvidoria:

- atender às reclamações/solicitações de usuários encaminhando-as aos setores competentes para resolução e procurando dirimir as questões suscitadas, usando um enfoque flexível visando à resolução do problema;

- oferecer assessoramento independente ao dirigente e usuário do sistema;

- supervisar o andamento das solicitações buscando o seu rápido atendimento.

Torna-se relevante salientar, ainda, que a Ouvidoria deve agir com transparência, isenção e autonomia, além de representar a própria empresa na escuta das demandas e outras manifestações geradas pelos cidadãos usuários, sendo o canal perfeito para efetivação dos direitos sociais e econômicos previstos em nossa República.

\section{A ECONOMIA DE COMUNHÃO}

A Economia de Comunhão (EdC) é uma possibilidade de gestão originada a partir do Movimento dos Focolares e tem como principal atributo a possibilidade de diminuir as diferenças sociais e a miséria enfrentada por certos grupos da população de todo o mundo.

Quando a Italiana Chiara Lubich (fundadora) propôs o projeto da EdC, ela não pensou em uma construção teórica e acadêmica, mas em uma resposta concreta a uma necessidade real da sociedade - a miséria.

A bibliografia sobre EdC começa com os escritos de sua fundadora, Chiara Lubich. São textos doutrinários, que caracterizam o movimento e o projeto como um movimento social, cujos fundamentos estão nos Evangelhos e na Doutrina Social da Igreja. Com efeito, no campo da cientificidade, algumas contribuições de profissionais que se vincularam ao movimento se apresentavam como perspectiva teórica. Mas, quando o projeto começou a se tornar realidade, ela convocou a comunidade acadêmica para estudá-lo (LUBICH, 1999, p.13).

Em 2006 já existiam 291 estudos acadêmicos, entre eles monografias, dissertações e teses sobre o assunto, catalogados no banco de dados do escritório central do projeto de EdC na Itália, segundo VILLARDI, LEITÃO e MARQUES (2007). Atualmente, é possível consultar inúmeros trabalhos acadêmicos (monografias, dissertações e teses) através do site http://www.ecodicom.net/tesi.php.

Vários trabalhos foram consultados a partir dos descritores elencados no resumo desta tese. Elegemos 6 (seis) deles, que foram cuidadosamente lidos e utilizados para a redação desta pesquisa acadêmica. 
A comunidade acadêmica começa, portanto, a manifestar interesse pela pesquisa nessa nova forma de economia solidária no sentido de partilha. Para ALMEIDA e LEITÃO (2003), seu potencial transformador da vida e da forma de gestão é o fato gerador do crescente interesse da comunidade acadêmica por aquele projeto que associa gestão de empresa com espiritualidade cristã.

Em seus 25 anos de existência, o projeto em pauta, EdC, se apresenta como uma via alternativa para a completa instrumentalização da vida empresarial e da vida associada como um todo. Uma alternativa para o consumismo e o utilitarismo dominantes na lógica do mercado, potencialmente capaz de transformar a atual forma de gestão capitalista. Essas empresas estão mudando o paradigma dominante e a ideologia produtivista que lhe dá sustentação, ao se orientarem para uma forma de economia solidária, de partilha. Talvez o mais importante sobre elas seja estarem demonstrando o quanto pode ser feito quando se tem vontade política para fazê-lo, diferenciando o que é factível da utopia, a partir de uma motivação de origem espiritual (PINTO e LEITÃO, 2006).

O projeto EdC luta contra a pobreza e a exclusão. É a cultura do dar e não a cultura do ter. Seus objetivos centram-se no ser humano e têm no critério o rendimento do capital investido na humanização das relações. É a pessoa e não o capital que está no centro da questão (ARAÚJO, 1998).

Conforme preleciona ARAÚJO (1998), existe finalmente um modo de dar que se abre ao indivíduo ou à pessoa, no respeito à sua dignidade, e suscita, inclusive na esfera da gestão das empresas, experiências do "dai e vos será dado", que às vezes se manifesta como uma receita inesperada ou na genialidade de uma solução técnica inovadora, ou na ideia de um novo produto de sucesso.

Segundo BIELA (1998), o movimento dos focolares tem quatro dimensões complementares entre si: social, moral, religiosa e econômica. Desta última, surgiu o então projeto da EdC.

Chiara Lubich, para reduzir as desigualdades, queria reunir empresas eficientes que gerassem lucros a serem partilhados: uma parte aos pobres, outra para o reinvestimento no próprio negócio e a terceira para a formação de um "homem novo" a partir dos colaboradores. Daí surgiu o projeto $\mathrm{EdC}$, reunião de organizações privadas em todos os sentidos, plenamente inseridas no mercado, que salvaguardam a propriedade particular dos bens, mas colocam o lucro - finalidade da empresa - em comunhão (BRUNI, 2005, p. 25).

Tratava-se, portanto, de uma iniciativa que levou a sério a comunhão, inclusive na concretude da vida econômica e civil.

\subsection{A Gestão da Economia de Comunhão}

A EdC propõe às organizações produtivas linhas para a gestão de uma empresa escritas à luz da vida e da reflexão de milhares de empresários e trabalhadores, seguindo o esquema das assim denominadas "sete cores", que é uma das intuições carismáticas (do início do Movimento dos Focolares) do modo de conceber e praticar a vida associada ao "carisma da unidade", do qual a EdC é a expressão. Disponíveis em: http://www.edc-online.org/br/empresas/linhas-para-gestao-de-uma-empresa.html (acesso em: 26 jan. 2016), encontram-se as linhas seguintes para uma gestão em EdC.

74 | Revista Científica da Associação Brasileira de Ouvidores/Ombudsman - Ano 1 - nº 1 - 2017/2018 


\subsubsection{Empresários, trabalhadores e empresas (vermelho)}

As empresas que aderem à Economia de Comunhão definem a própria "missão empresarial" adotando a comunhão como valor fundamental da própria organização, em todos os níveis.

Para que isso seja atuado, as funções e os papéis na empresa são definidos com clareza e exercitados com espírito de serviço e de responsabilidade. A forma da administração é participativa. Os objetivos empresariais são compartilhados e adequadamente verificados de forma transparente, tendo uma atenção particular para a qualidade das relações entre todos os sujeitos envolvidos e, de modo especial, à comunhão com os outros empresários de EdC, com a comissão regional e com as associações EdC locais e internacionais. Quando a empresa obtém lucros, os empresários e os sócios se comprometem em compartilhar esses lucros para destiná-los, respeitando os procedimentos típicos nas várias formas de empresa e das situações sociais nas quais trabalham e atribuindo às três destinações apresentadas em seguida igual importância:

- À ajuda para pessoas em situação de miséria (pobreza) através de diversas formas de intervenções voltadas para a inclusão comunitária e produtiva.

- Ao desenvolvimento da empresa, ou seja, à sua consolidação, à melhora da qualidade de bens e serviços e, sobretudo em países onde o trabalho é escasso, à geração de postos de trabalho, e enfim, onde isso é possível, também à remuneração dos sócios.

- À difusão da cultura de comunhão e do "dar". No caso em que a adesão à EdC não é ainda compartilhada com todos os sócios, o empenho em doar os lucros conforme os objetivos do projeto é limitado às cotas de quem aderiu.

\subsubsection{O relacionamento com os clientes, os fornecedores, os financiadores, a sociedade civil e os sujeitos externos (alaranjado)}

Os membros da empresa se empenham com profissionalismo para construir e reforçar relacionamentos sadios e abertos com os clientes, os fornecedores e a comunidade do território nos quais trabalham, cuja custódia e melhoramento sentem como parte integrante da própria missão.

A empresa se relaciona de forma leal e civil com os concorrentes, fornecedores, clientes, a sociedade civil e a Administração Pública, que sente como parceiros essenciais para alcançar o bem comum. Além disso, o empresário e os trabalhadores das empresas de EdC promovem o seu espírito e a sua mensagem, apresentando as suas ideias e experiências em congressos, seminários e encontros, já que consideram parte da própria "vocação" difundir essa nova visão econômica. Não devem se contentar em viver a EdC, e sim torná-la conhecida a muitos, com uma atenção especial aos jovens, a quem acolhem também em períodos de formação ou de estágio. Aqui, o Ombudsman atua de forma integral neste contexto empresarial.

\subsubsection{Espiritualidade e ética (amarelo)}

O trabalho da EdC é visto como uma oportunidade de crescimento não só profissional, mas também espiritual e ético. A empresa se empenha no respeito concreto das leis e trabalha para a 
mudança e no seu melhoramento. Mantém um comportamento correto em relação às autoridades fiscais, aos sindicatos e aos demais órgãos institucionais e tem consciência de que a qualidade de vida no trabalho é dimensão essencial para a realização da pessoa e para o desenvolvimento da sua vocação como trabalhador e como ser humano.

Quem trabalha nas empresas de EdC aprende a valorizar também as dificuldades e o sofrimento nos lugares de trabalho, fazendo desses aspectos oportunidades preciosas de crescimento e de amadurecimento. Na definição da natureza e da qualidade dos próprios produtos, a empresa se empenha não somente com o respeito das próprias obrigações contratuais, mas também em avaliar os efeitos dos produtos no bem-estar das pessoas às quais são destinados e sobre o ambiente.

\subsubsection{Qualidade de vida, felicidade e relações (verde)}

Um dos objetivos fundamentais de uma empresa de EdC é tornar-se uma verdadeira comunidade. Com essa finalidade, são programados encontros periódicos para verificar a qualidade dos relacionamentos interpessoais e para ajudar a resolver as situações de conflito, recorrendo regularmente aos assim chamados "instrumentos" de comunhão, entre os quais o colóquio - uma conversa periódica, dos trabalhadores com os responsáveis, pelo menos uma vez por ano -, momentos de avaliação comunitária e de "correção fraterna" entre todos os membros da empresa que experimentam, dessa forma, uma fraternidade e uma igualdade entre todos, que antecede as necessárias diferenças de função e de responsabilidade na empresa; a escuta por parte dos gestores de eventuais protestos e desacordos, bem como de sugestões; a troca de experiências durante momentos de encontro previstos. A empresa de $\mathrm{EdC}$ sabe que, sem exercitar esses instrumentos de comunhão, a vida relacional empresarial empobrece, às custas também das performances econômicas.

É dada uma atenção especial à saúde física, ao esporte e ao cuidado com o ambiente, já que a comunhão abraça também a natureza e a corporeidade.

Para o cuidado com os relacionamentos, a empresa de EdC dá importância à festa também nas atividades empresariais do dia a dia (aniversários, nascimentos, partidas etc.), em que se reforçam os relacionamentos e a pertença à comunidade de trabalho, recursos preciosos, principalmente em momentos de crise.

\subsubsection{Harmonia no ambiente de trabalho (azul)}

A beleza e a harmonia dos lugares de trabalho são o primeiro cartão de visita da empresa de $E d C$, já que a comunhão é também beleza, sem a necessidade do luxo, e com discrição. Os ambientes são expressão da harmonia dos relacionamentos, bem como parte das relações empresariais. A higiene, a limpeza, a ordem são parte da cultura da $\mathrm{EdC}$, de forma que a sua harmonia faça os trabalhadores, proprietários, clientes, fornecedores e visitantes sentirem-se bem.

Por isso, garante-se o respeito das normas de segurança, a ventilação necessária, níveis toleráveis de barulho, iluminação adequada e tudo o que facilita a qualidade das relações dentro e fora 
da empresa. A dimensão da beleza é tida com máxima consideração, mesmo quando a empresa entra, direta ou indiretamente, em contato com a pobreza, consciente de que a primeira forma de cuidado com toda forma de miséria é a atenção ao outro, e a dimensão da beleza apresenta isso da melhor forma.

\subsubsection{Formação, instrução e sabedoria (anil)}

A empresa favorece entre os seus membros a instauração de um clima de confiança recíproca, no qual seja natural colocar livremente à disposição os próprios talentos, ideias e competências em favor do crescimento profissional dos colegas e para o progresso da empresa.

A primeira escola de formação é sempre a comunidade empresarial, nos seus diversos relacionamentos. Além disso, a direção adota critérios de seleção de pessoal e de programação do desenvolvimento profissional para os trabalhadores a ponto de facilitar a criação de uma atmosfera de bem-estar. A empresa dá oportunidades de atualização e de aprendizagem contínua, favorecendo a formação profissional e para a cultura de comunhão do próprio pessoal, com uma atenção particular aos jovens de dentro e de fora da empresa.

Finalmente, o empresário e os trabalhadores da EdC cultivam a própria humanidade e os próprios interesses fora e dentro da empresa, com uma atenção especial ao desenvolvimento da cultura e do pensamento econômico e, por isso, participam de escolas e congressos para serem sempre mais capazes de ter argumentos sobre a própria visão empresarial e cultural.

\subsubsection{Comunicação (violeta)}

Os empresários que aderem à EdC trabalham constantemente para criar um clima de comunicação aberto e sincero, que ajude na troca de ideias e de informações em todos os níveis de responsabilidade. Com esta finalidade, adotam os instrumentos oportunos de prestação de contas periódica, seja dentro da empresa, seja externamente (por exemplo, "balanço social"), que mostrem nos atos (nas ações) o valor social gerado pelos diversos sujeitos envolvidos nesta atividade empresarial. Mais uma vez, a Ouvidoria com seu papel de grande importância na comunicação empresarial.

Não existe comunhão sem comunicação. As empresas implantadas conforme a EdC, também no intuito de desenvolver relacionamentos econômicos reciprocamente úteis e produtivos, utilizam os mais modernos meios de comunicação para estarem ligadas entre si em nível local e internacional.

Os empresários que aderem à EdC, conscientes da validade cultural e política que o sucesso do projeto comum pode comportar, mantêm sempre vivo entre eles, em nível local e internacional, um espírito de ajuda recíproca e de solidariedade. E se colocam em rede com todos os homens e as mulheres de boa vontade que queiram contribuir, sinceramente, para um mundo mais justo, fraterno, unido. 


\section{A INTERFACE ENTRE A BIOÉTICA, A ECONOMIA DE COMUNHÃO E O PAPEL DO OMBUDSMAN}

A EdC como apresentada refere-se a empresas que buscam uma alternativa ao modelo administrativo vigente na maioria das organizações, propondo um estilo de agir econômico com as características da gratuidade, da abertura do outro e da solidariedade, apesar de atuarem, principalmente, em setores econômicos e com fins lucrativos.

Mas é necessário que as empresas participantes da proposta do EdC estejam em sintonia com a Bioética como área de conhecimento constituída pela convergência de diversos saberes conduzindo-as ao caminho certo na busca dos valores e objetivos almejados.

São elas conhecidas como empresas participantes da proposta de EdC, que visam oferecer uma resposta ao drama da extrema pobreza das populações privadas dos direitos humanos mais fundamentais e constituem-se, ainda, em um esforço de integração entre a gestão de empresas e os princípios contidos em uma base religiosa para transformar o modelo econômico dominante. Não se confunde a proposta da EdC com um simples caso de filantropia ou de participação nos lucros, mas trata-se, sim, do sentido que funcionários e empresários atribuem ao trabalho que realizam. Tais empresas vêm imprimindo uma prática alternativa ao sistema vigente de mercado (a acumulação de capital não é o seu objetivo).

No contexto acima descrito, surge a intermediação da Bioética. Lembrando que esta, enquanto ética da vida diante da falência de valores universais, proporciona uma tomada de consciência das grandes transformações que caracterizam a situação social e histórica que constituem até os dias de hoje a realidade. Além disso, ela permeia a ética com o fim de possibilitar reflexões que resultem em solução aos problemas atuais e concretos, favorecendo a consciência de valores éticos antes de se adotarem posturas e normas (POTTER, 1988).

Daí, para que seja possível a efetivação dessa proposta especialmente na Gestão Universitária, com a possibilidade real de transformação dos seus alunos, professores e funcionários técnico-administrativos em cidadãos com respeito total à sua dignidade, surge a necessidade da implantação de um serviço de Ouvidoria, com atuação clara, precisa e transparente, uma vez que estar dentro da organização para buscar racionalidade e ter visão pontual do foco do problema facilita encontrar soluções. Dessa forma, o Ombudsman na EdC com uma visão bioética ganha destaque e importância no mercado por prover as organizações educacionais de uma fonte relevante de dados e informações a respeito dos usuários dos serviços oferecidos, sobre a imagem e o nível de excelência da Instituição. Com isso facilita a gestão na tomada de decisões em direção à efetividade de todo e qualquer serviço prestado. A intensificação e eficiência da comunicação podem trazer benefícios às diferentes áreas da organização.

\section{CONSIDERAÇÕES FINAIS}

Todos nós, invariavelmente e de forma constante, nos deparamos com alguma experiência ligada a questões de Bioética como, por exemplo, na saúde (aborto, pesquisas com seres vivos), na 
família (adoção, inseminação, homossexualidade), no trabalho (gestão forçada, assédio moral), no meio ambiente (desmatamento, reflorestamento e catástrofes), no cotidiano (compras de produtos piratas), na política (corrupção), e assim, em todas as situações que envolvem pessoas dentro de uma sociedade, a bioética estará presente.

A Bioética surge, portanto, como um dos principais sinais de esperança da humanidade.

É nesse contexto de "luzes e sombras", inquietações e esperanças que surge a Bioética como um componente vital de resgate da dignidade do ser humano e proteção da vida cósmicoecológica. O século XXI será marcado pela ética ou então corremos o risco de não existir! (PESSINI, BERTACHINI e BARCHIFONTAINE, 2014, p. 4)

A valorização da dignidade do profissional em qualquer esfera empresarial sempre deve ser a premissa para que o empresário supere suas expectativas no mercado competitivo. O Ombudsman tem função importante nesse contexto empresarial visando o resgate da cidadania e dos direitos humanos.

Embora o poder diretivo seja exclusivo do empresário, da mesma forma que o dever de obediência do empregado, evidente que esses papéis devem ser exercidos com moderação no contexto do Contrato de Trabalho.

Constatamos que a garantia da dignidade profissional dos envolvidos na gestão universitária requer basear-se em Referenciais do Sistema Aberto Bioético, como a Dignidade, Vulnerabilidade, Alteridade, e também os princípios Bioéticos como a Autonomia, Justiça, Beneficência e Não Maleficência. A EdC também se fundamenta em princípios que geram interação viva e possível de desenvolvimento empresarial, pautada no cristianismo e nas lições de Chiara Lubich, fundadora do movimento dos Focolares, baseada nos princípios da EdC.

Um dos grandes desafios que a prática da EdC consegue superar são as trocas humanas de respeito mútuo. Ela traz ao mundo da gestão universitária interessantes propostas para uma alternativa ao modelo administrativo vigente, onde o lucro é o elemento preponderante nas intervenções empresariais, através de um modelo de agir econômico com as características da gratuidade, da abertura ao outro e da solidariedade, apesar de atuarem principalmente perseguindo a finalidade lucrativa.

Entendemos que, sob a perspectiva de uma ação coletiva (empresários da educação, corpo técnico-administrativo, incluindo-se o Ombudsman e comunidade acadêmica), é possível estender para as Escolas Acadêmicas as práticas da EdC como sendo capazes de realizar mudanças transformadoras pela aprendizagem, em que predominam os aspectos sociais no entendimento da realidade organizacional, em vez de apenas aspectos técnicos e econômicos.

Com efeito, o sujeito passa a ser o protagonista de sua história e o Ombudsman a ponte para esse resgate.

As Ouvidorias, nesse sentido, têm se revelado instrumentos de grande importância no processo de humanização das estruturas organizacionais e canais ágeis de participação do cidadão, considerando-se o modelo de gestão participativa atualmente almejado e estimulado, e são entendidas estrategicamente como grande captadoras e processadoras de ideias para melhoria da qualidade de serviço prestados à sociedade, exatamente como preconizado pelas empresas que adotam a gestão por meio da Economia de Comunhão e, portanto, precisam implantar esse serviço 
de forma imediata visando alcançar o instrumento abrangente que levará, sem sobra de dúvida, à transformação da administração universitária no crescimento tão almejado e esperado conforme as modernas e bem-sucedidas práticas de mercado.

\section{REFERÊNCIAS}

AGUIAR, Maria R. M. G. Assédio Moral: problema antigo, interesse recente. 2015. 2. Disponível em: http://egov.ufsc. br/portal/sites/default/files/anexos/23353-23354-1-PB.pdf. Acesso em: 10 ago. 2015.

ARAÚJO, Vera. Economia de comunhão e comportamentos sociais. In: COSTA et al. Economia de comunhão. São Paulo: Cidade Nova, 1998.

BADIM, Maria Paola Mattion. Conhecimento da percepção de professores de enfermagem de ensino superior sobre o assédio moral: Reflexões bioéticas. Tese de Doutorado em Bioética defendida no Centro Universitário São Camilo, SP, 2014.

BADIM, Maria Paola Mattion; HOSSNE, William Saad; FERRARI, Maria Auxiliadora Cursino. A percepção de professores de enfermagem de ensino superior sobre assédio moral: reflexões bioéticas. Revista Bioetikós - Centro Universitário São Camilo, 2014;8(3):271-280.

BARCHIFONTAINE, Christian de Paul. Bioética e Início de vida: alguns desafios. São Paulo: Ideias e Letras, Centro Universitário São Camilo, SP, 2004.

BARCHIFONTAINE, Christian de Paul. Formação Cidadã do Enfermeiro: estudo comparativo sobre a capacitação do enfermeiro para a cidadania, na formação graduada, em Portugal e no Brasil. Tese de Doutorado. São Paulo, 2012.

BARROS, Alice Monteiro. Curso de Direito do Trabalho: estudos em memória de Célio Goyatá. 1 ed. v. I. São Paulo: LTr, 1997.

. Poder Hierárquico do Empregador: Poder Diretivo. São Paulo: LTr, 1997.

BOFF, Leonardo. A águia e a galinha: uma metáfora da condição humana. Petrópolis: Editora Vozes, 1997.

BRUNI, Luigino (Org.). Economia de Comunhão: Uma cultura econômica em várias dimensões. Vargem Grande Paulista, SP: Editora Cidade Nova, 1999.

Comunhão e as novas palavras em economia. Vargem Grande Paulista, SP: Editora Cidade Nova, 2005.

COLOMBO, Sonia Simões. Gestão Universitária: Os caminhos para a excelência. Porto Alegre: Penso Editora, 2013.

COMISSÃO DO DIREITO TRABALHO, MINICARTILHA DA OAB PIAUÍ. O Assédio Moral no Ambiente de Trabalho. Piauí, 2015, 24 p. Disponível em:<https:// www.oabpi.org.br>. Acesso em: 12 set. 2015.

DELGADO, Maurício Godinho. Curso de Direito do Trabalho. São Paulo: LTr, 2007.

GONÇALVES, Heloísa Helena A. Borges Q.; LEITÃO, Sérgio Proença. Empresas da Economia de Comunhão: O caso Femaq. RAP, Rio de Janeiro, v. 35, n. 6, p. 33-59, nov/dez 2001.

HOSSNE, William Saad; SEGRE, Marcos. Dos referenciais da Bioética: A alteridade. Revista Bioetikós - Centro Universitário São Camilo, São Paulo, v. 5, n. 1, p. 35-40, 2011.

HOSSNE, William Saad. Bioética: Princípios ou referenciais. Revista O Mundo da saúde. Centro Universitário São Camilo, São Paulo, v. 30, n. 4, p. 673-676, out/dez 2006.

HOSSNE, William Saad. Dos referenciais da Bioética: a vulnerabilidade. Revista Bioetikós - Centro Universitário São Camilo, São Paulo, v. 3, n. 1, p. 41-51, 2009.

LEBRUN, Gérard. O que é o poder. São Paulo: Brasiliense, 1999.

MANCUSO, Rodolfo Camargo. Interesses Difusos. São Paulo: Editora Revista dos Tribunais, 1990. p. 51.

MESQUITA, Luiz José de. Direito Disciplinar do Trabalho. 2. ed. São Paulo: LTr, 1991.

80 | Revista Cientifica da Associação Brasileira de Ouvidores/Ombudsman - Ano 1 - nº 1 - 2017/2018 
NASCIMENTO, Amaury Mascaro. Iniciação ao Direito do Trabalho. 33. ed. São Paulo: LTr, 2007.

ODONE, Ivar. Ambiente de Trabalho: A luta dos trabalhadores pela Saúde, 1995.

OGUISSO, Taka; ZOBOLI, Elma Lourdes Campos Pavone. Ética e bioética: desafios para a enfermagem e a saúde. Barueri, SP: Manole, 2006.

PESSINI, Leocir. Bioética: Um grito por dignidade de viver. São Paulo: Paulinas, 2008.

PESSINI, Leocir; BERTACHINI, Luciana; BARCHIFONTAINE, Christian. Bioética, cuidado e humanização: Das origens à contemporaneidade. São Paulo: Centro Universitário São Camilo, Instituto Brasileiro de Controle do Câncer e Edições Loyola, 2014.

ROCHA, Júlio César de Sá. Direito Ambiental e Meio Ambiente do Trabalho. São Paulo: LTr, 1.997 p. 50. SADY, João José. Direito do Meio Ambiente de Trabalho. São Paulo: LTr, 2000.

SILVA, Guido Vaz. Poder e decisão em empresas de economia de comunhão: um estudo de caso. Dissertação de Mestrado: Pontifícia Universidade Católica do Rio de Janeiro. Orientador: LEITÃO, Sérgio Proença. 2008.

SILVA, Ivan de Oliveira. Biodireito, bioética e patrimônio genético brasileiro. São Paulo: Pillares, 2008.

VIEIRA Sonia; HOSSNE William. Metodologia científica para a área da saúde. Rio de Janeiro.

VISMONA, Edson Luis (Org.). A Ouvidoria brasileira - Dez Anos de Associação Brasileira de Ouvidores/Ombudsman. São Paulo: Imprensa Oficial, 2007.

ZAMAGNI, S. Fundamento e significado da experiência da economia de comunhão. In: BRUNI, L. (Org.). Economia de comunhão. Vargem Grande Paulista, SP: Editora Cidade Nova, 2002.

ZOBOLI, Elma Lourdes Campos Pavone. Ética e Administração Hospitalar. São Paulo: Loyola, 2003. 